\title{
Associative processes in early olfactory preference acquisition: Neural and behavioral consequences
}

\author{
REGINA M. SULLIVAN, DONALD A. WILSON, and MICHAEL LEON \\ University of California, Irvine, California
}

\begin{abstract}
Acquisition of behavioral conditioned responding and learned odor preferences during olfactory classical conditioning in rat pups requires forward or simultaneous pairings of the conditioned stimulus (CS) and the unconditioned stimulus (US). Other temporal relationships between the CS and US do not usually result in learning. The present study examined the influence of this CS-US relationship upon the neural olfactory bulb modifications that are acquired during early classical conditioning. Wistar rat pups were trained from Postnatal Days (PN) 1-18 with either forward (odor overlapping temporally with reinforcing stroking) or backward (stroking followed by odor) CS-US pairings. On PN 19, pups received either a behavioral odor preference test to the odor CS or an injection of ${ }^{14} \mathrm{C} 2-\mathrm{DG}$ and exposure to the odor CS, or olfactory bulb single unit responses were recorded in response to exposure to the odor CS. Only pups that received forward presentations of the CS and US exhibited both a preference for the CS and modified olfactory bulb neural responses to the CS. These results, then, suggest that the modified olfactory bulb neural responses acquired during classical conditioning are guided by the same temporal constraints as those which govern the acquisition of behavioral conditioned responses.
\end{abstract}

When olfactory cues are paired with tactile stimulation, infant rats learn conditioned responses to such odors (Sullivan, Brake, Hofer, \& Williams, 1986; Sullivan \& Hall, 1988; Sullivan, Hofer, \& Brake, 1986). The tactile stimulation mimics maternal contact (Barnett \& Walker, 1974; Butler, Suskind, \& Schanberg, 1968; Evoniuk, Kuhn, \& Schanberg, 1978; Kuhn, Butler, \& Schanberg, 1978) and has been shown to be reinforcing to neonates in a classical conditioning paradigm (Sullivan \& Hall, 1988). This form of learning can be critical for the survival of the young, can be acquired quite rapidly (Sullivan \& Leon, 1987), has a sensitive period for acquisition (Woo \& Leon, 1987) and is retained into adulthood (Coopersmith \& Leon, 1986). The behavioral consequences of this form of learning conform to the constraints of classical conditioning (Sullivan \& Hall, 1988), suggesting that associative learning is the underlying process of acquisition.

While learning and information storage are believed to be distributed processes involving multiple central nervous system (CNS) structures, the most robust neural consequences of early olfactory conditioning yet described occur in the olfactory bulb. That is, in addition to behavioral preference acquisition, early olfactory learning modifies two characteristics of the olfactory bulb response

This work was supported by NINCDS Grant NS26100 and PEW Foundation Funds to Regina M. Sullivan, Grant NS 21484 from NINCDS to Michael Leon, who holds a Research Scientist Development Award MH 00371 from NIMH, and NSF Grant BNS8606786 to Donald A. Wilson and Michael Leon. Correspondence may be addressed to Regina M. Sullivan, Department of Psychology, University of Oklahoma, Norman, OK 73019 . to the conditioned odor. First, there is enhanced metabolic activity (increased uptake of ${ }^{14} \mathrm{C}$-labeled 2deoxyglucose [2-DG]) in a restricted, odor-specific region of the glomerular layer of the olfactory bulb during a subsequent exposure of a conditioned odor (Coopersmith \& Leon, 1984), which appears to be dependent upon the pairing of odor and tactile stimulation (Sullivan \& Leon, 1986). Second, the output neurons of the olfactory bulbmitral/tufted cells-are suppressed during subsequent exposure to the conditioned odor (Wilson, Sullivan, \& Leon, 1985,1987 ). This suppression is confined to neurons in proximity to the focus of enhanced glomerular 2-DG uptake (Wilson \& Leon, 1988b). While an effort has been made to interpret these two differing neural phenomena within the context of a single model of the neural consequences of early olfactory conditioning (Leon et al., 1987), the possibility remains that the neural phenomena are unrelated. One way to attempt to dissociate the neural phenomena is to determine whether both of them are due to associative processes, as has been demonstrated for the behavioral preference (Sullivan \& Hall, 1988).

To ascertain the specificity of the neural phenomena to an associative process, it is critical that both conditioned and control groups receive identical odor and tactile stimulation during conditioning. The only difference between groups would be that the conditioned group should receive odor and tactile stimulation concurrently (forward conditioning), while the control group should receive the stimuli sequentially (backward conditioning). Backward conditioning does not generally result in a conditioned behavioral response (Pavlov, 1927; but see Rescorla, 1967), and this is consistent with results obtained from olfactory 
learning studies in infant rats (Johanson \& Hall, 1982; Johanson, Polefrone, \& Hall, 1984; Johanson \& Teicher, 1980; Sullivan \& Hall, 1988).

In the present studies, pups received the olfactory conditioned stimulus (CS) and the reinforcing unconditioned stimulus (US) either concurrently (forward) or sequentially (backward). Behavioral odor preferences, glomerular uptake of 2-DG and the responsiveness of single $\mathrm{mitral} /$ tufted cells near the 2-DG foci to the trained odor were then assessed.

\section{METHOD}

\section{Subjects}

The subjects were 25 male and female Wistar rats (offspring from Hilltop Lab Animals, Scottsdale, PA) at Postnatal Day (PN) 19. No more than 1 pup from a litter was used in an experimental condition. Dams were housed in rectangular polypropylene cages (34 $\times 29 \times 17 \mathrm{~cm})$ lined with wood chips in a temperature- $\left(23^{\circ} \mathrm{C}\right)$ and light- $(0800-2000 \mathrm{~h})$ controlled room. Births were checked at 0800 and $1700 \mathrm{~h}$. The day of birth was considered to be PN 0 . Food and water were available ad lib. Mothers were placed on a sucrosebased, fat-sufficient diet (Teklad test diet TD 69446) on the day of parturition. The diet suppresses the dominant maternal odor by suppressing the cecal bacterial population (Leon, 1974). Both training and testing were performed during the early part of the light phase (0800-1200 h).

\section{Conditioning Paradigm}

The conditioning protocol consisted of 18 training sessions, with an intertrial interval of $24 \mathrm{~h}$, starting on PN 1 . Preceding each training session, the pups were removed from the dam and placed in individual glass cylinders. The pups received a 10 -min adaptation period, followed by either of two training regimes: (1) forward CS-US (odor and stroking)-the pups were presented with a 10min odor presentation, with the last 9 min overlapping with stroking; and (2) backward US/CS (stroking > odor)-the pups were presented with $9 \mathrm{~min}$ of stroking, followed immediately with $10 \mathrm{~min}$ of odor. The CS was a peppermint odor (Schilling) presented at a concentration of $1: 10$ dilution. The odor delivery and concentration were controlled by a flow-dilution olfactometer at a flow rate of 2 liters $/ \mathrm{min}$. The tactile stimulation consisted of stroking all body areas of the pup with a sable-hair brush with a vigor sufficient to elicit body movement in the pups. This stimulation mimics maternal contact (Barnett \& Walker, 1974; Butler et al., 1968; Evoniuk et al., 1978; Kuhn et al., 1978; Schanberg, Evoniuk, \& Kuhn, 1984) and has reinforcing properties for pups (Sullivan \& Hall, 1988). Following each training session, the pups were returned to the nest.

\section{Testing}

On PN 19, the pups received one of three tests: a behavioral test to assess learning $(n=8)$, a 2-DG test $(n=10)$, or extracellular recording of single mitral/tufted cells ( $n=7$ pups; $n=23$ cells).

Behavior test. The behavior test was a two-odor choice test used to determine whether pups learned a preference for the odor (Cornwell-Jones \& Sobrian, 1977). The test apparatus consisted of a Plexiglas box $(33 \times 21 \times 14 \mathrm{~cm})$ with a small-grid wire mesh floor $(1 \times 1 \mathrm{~cm})$, divided in half by a "neutral zone" that ran perpendicular to the long length of the box. The CS peppermint odor ( 1 cc peppermint extract over $500 \mathrm{ml}$ clean wood chips) was placed on one side of the neutral zone under the wire mesh, and the familiar pine wood chips (the same type of shavings as were used in the nest) were placed on the other side. The pups received three consecutive 1-min trials in the test box. A trial began by placing a pup on the neutral zone, parallel to the long side of the box. When the pup's head and forepaws crossed above an odor, the timer for that odor was started. At the end of the test, the total time the pup spent over each odor was recorded.

$2-D G$ autoradiography. Pups were also used to assess focal ${ }^{14} \mathrm{C}$ 2-deoxyglucose (2-DG; Gallistel et al., 1982; Sokoloff et al., 1977) uptake in the glomerular layer of the olfactory bulb during exposure to peppermint odor. Immediately prior to odor delivery on PN 19, the pups were injected with ${ }^{14} \mathrm{C} 2$-DG $(20 \mu \mathrm{Ci} / 100 \mathrm{~g} \mathrm{bw}$, s.c. $)$ and then placed in a glass test cylinder $(29 \times 11 \mathrm{~cm})$ covered with an airtight plastic lid. Peppermint odor (1:10 dilution) entered the canister at 2 liters/min for 1 -min periods, after which time the airflow ceased and respiration was recorded for $4.75-\mathrm{min}$ periods. This cycle was repeated 8 times for a total of $45 \mathrm{~min}$.

Following the 45-min odor delivery (Kelly \& McCullough, 1981), the pups were rapidly decapitated and their brains immediately frozen $\left(-45^{\circ} \mathrm{C}\right)$, stored at $-70^{\circ} \mathrm{C}$ and cut into $20-\mu \mathrm{m}$ sections at $-18^{\circ} \mathrm{C}$. The brain sections and ${ }^{14} \mathrm{C} 2-\mathrm{DG}$ standards were then exposed to Kodak SB5 X-ray film for 10 days. The resulting autoradiographs were analyzed with the aid of a computer-based digital image processor (Spatial Data) that allowed pseudocolor imaging and two-dimensional quantitative optical densitometry. To quantify 2DG uptake, the computer constructed a calibration curve that related the gray value of ${ }^{14} \mathrm{C}$ standards that were exposed with the brain sections to that of the previously determined ${ }^{14} \mathrm{C}$ tissue equivalent. The computer then linearized this function, thereby allowing the gray values of the autoradiographs to be translated into ${ }^{14} \mathrm{C}$ levels, and hence 2-DG uptake by the tissue.

The autoradiographs were then optically scanned for the odorspecific 2-DG spatial pattern and sections in this area were analyzed. The odor-specific pattern of focal 2-DG uptake (Astic \& Catarelli, 1982; Astic \& Saucier, 1982; Greer, Stewart, Kauer, \& Shepherd, 1981; Jourdan, Duveau, Astic, \& Holley, 1980; Sharp, Kilduff, Bzorgchami, Heller, \& Ryan, 1983; Stewart, Kauer, \& Shepherd, 1979) is easily identified and limited to the glomerular layer (Sharp, Kauer, \& Shepherd, 1975). In each section, 5 readings (each 9 pixels) were taken within the peppermint-responsive areas of the glomerular layer, which are 1.5-2.2 mm from the rostral pole of the olfactory bulb. Five readings were also taken in the regions of the glomerular layer that was not associated with a 2-DG focus. Five additional readings were taken in the periventricular core of the olfactory bulb. A ratio of glomerular layer to periventricular core 2-DG uptake was then calculated. The periventricular core was chosen as a baseline measure of 2-DG uptake because it has consistently low levels of 2-DG uptake in response to odor presentations (Jourdan et al., 1980). Thus, a ratio of average 2-DG uptake in the glomerular region to that of the periventricular core enables one to produce relative uptake measurements within the same section. This procedure eliminates interpretation problems due to minute differences in section thickness and background activity when the autoradiographs are analyzed.

Neurophysiology. Additional pups were anesthetized with urethane $(1.5 \mathrm{~g} / \mathrm{kg})$ and prepared for neurophysiological analysis. The animals were mounted in a stereotaxic apparatus, and their body temperature was maintained with a thermistatically controlled heating pad. A single bipolar stimulating electrode was placed in the lateral olfactory tract (LOT), and single-unit responses were recorded in the olfactory bulb with a glass microelectrode filled with $0.5 \mathrm{M} \mathrm{KCl}$. Single-unit recordings were made from mitral/tufted cells along the lateral aspect of the olfactory bulb, 1.5-2.2 mm from the rostral pole of the bulb, in the area of focal 2-DG uptake to peppermint (Wilson \& Leon, 1988b). Mitral/tufted cells were identified by LOT evoked response morphology, and by the ability to antidromically activate them from the LOT. Odors were delivered to the external nares through glass tubing. The animals respired normally. The odor concentration was controlled with flow-dilution olfactometers (1:10, 2-liter/min flow rate). Peppermint and isoamyl acetate were used as stimuli. The responses 
to repeated 4-sec odor stimuli were analyzed by comparing mean firing rate during a 10-sec pre-odor baseline with firing rate during the 4-sec odor stimulus. The responses were categorized as excitatory, suppressive, or no response, according to specific criteria previously described (Wilson et al., 1987; Wilson \& Leon, 1988b). An excitation ratio was then calculated for both training groups as the percent cells excited/total percent responsive.

\section{RESULTS}

The pups in the forward conditioning group exhibited a preference for the odor CS, while the pups in the backward conditioning group did not. The forward conditioning pups spent more time over the conditioned odor than did the pups in the backward conditioning group ( $t=$ $4.38, p<.01$; see Figure 1). Furthermore, only the pups in the forward conditioning group spent more time over the peppermint conditioned odor than over the familiar pine odor $(t=5.41, p<.01)$. These behavioral results replicate previous results, which indicate that backward presentation of a CS and UCS does not result in learning in infant rats (Johanson \& Hall, 1982; Johanson, Polefrone, \& Hall, 1984; Johanson \& Teicher, 1980; Sullivan \& Hall, 1988).

Similarly, the pups in the forward conditioning group exhibited the enhanced glomerular layer focal 2-DG uptake previously demonstrated to be associated with olfactory learning (Sullivan \& Leon, 1986). This was not exhibited by the pups in the backward conditioning group. The forward conditioning pups exhibited significantly more focal 2-DG uptake than did the pups in the backward conditioning group in the peppermint-responsive areas of the olfactory bulb glomerular layer $(t=2.49$, $p<.01$; see Figure 2). No difference in 2-DG uptake was found between the two groups in nonpeppermintresponsive glomerular layer areas, in the periventricular core, or in the number or distribution of peppermintresponsive areas. Thus, this enhanced uptake appeared to be limited to the odor-specific pattern of 2-DG uptake found within the glomerular layer.

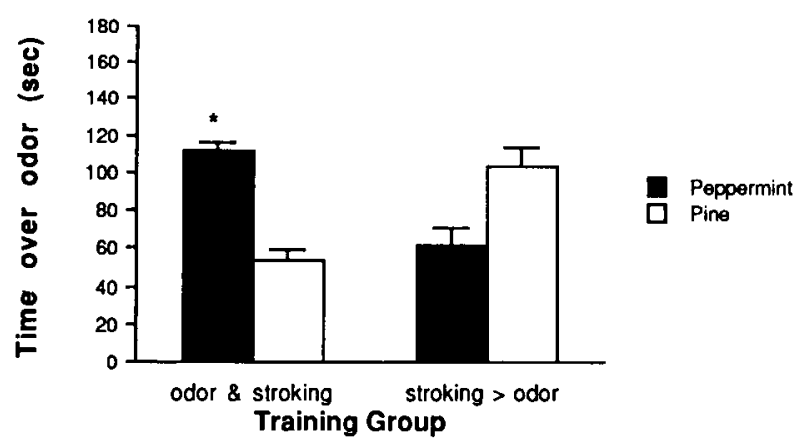

Figure 1. Mean number of seconds $(+S E)$ spent over the peppermint CS and the familiar pine odor in the two-odor choice test for pups in the odor and stroking (forward) and the stroking $>$ odor (backward) conditioning groups. Odor and stroking pups spent significantly more time over peppermint than did stroking $>$ odor pups $\left({ }^{*} p<.01\right)$.

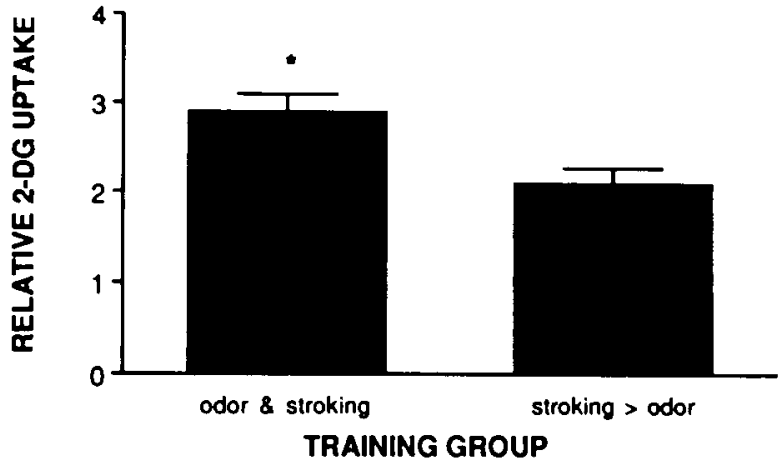

Figure 2. Relative focal 2-DG uptake in the spatially odor-specific areas of the olfactory bulb during test exposure to peppermint odor CS for the odor and stroking (forward) and the stroking $>$ odor (backward) conditioning groups. Forward conditioned pups demonstrated enhanced focal 2-DG uptake compared to backward conditioned pups $(* p<.01)$

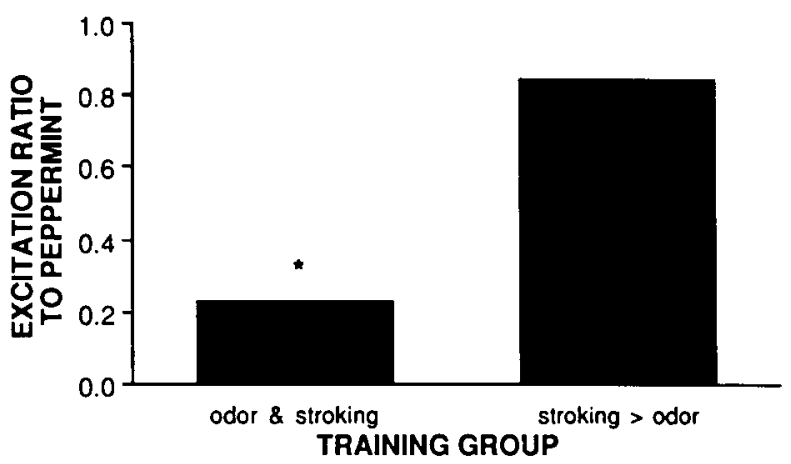

Figure 3. Mitral/tufted cell excitation ratios (percent excited/total percent responsive) to the $\mathrm{CS}$ in the odor and stroking (forward) and the stroking > odor (backward) conditioning groups. Cells in forward conditioned pups demonstrated a significant decrease in excitation ratio compared to cells in backward conditioned pups $\left({ }^{*} p<.01\right)$.

The enhanced focal 2-DG uptake was not associated with a modified respiratory response to the CS. No difference between the treatment groups was detected in total number of respirations or in the respiration frequency distribution during the 2-DG test. These data are consistent with previous correlative studies of 2-DG uptake and respiration (Sullivan \& Leon, 1986), and with a study in which respiration rate was artificially controlled during 2-DG uptake (Sullivan, Wilson, Kim, \& Leon, 1988).

In addition to the enhanced glomerular layer response to the CS, the olfactory bulb output neurons-mitral/tufted cells-demonstrated a modified response to the CS only in the forward conditioning group (see Figure 3). In the backward conditioning group, $18 \%$ of the cells were excited by the CS, $3 \%$ were suppressed, and $79 \%$ of the cells were nonresponsive. This response pattern corresponds well with previous reports of response patterns in odor-naive pups (Wilson et al., 1985, 1987; Wilson \& Leon, 1988b). Mitral/tufted cells in the forward conditioning group, however, demonstrated a significant 
reversal in response pattern to the $\mathrm{CS}$, with the majority of responsive cells being suppressed (10\%), and substantially fewer (3\%) being excited (forward vs. backward response pattern; $\chi^{2}=20.1, p<.01$ ). The excitation ratio to the $\mathrm{CS}$ for the forward conditioning group was thus substantially different from that for the backward conditioning group ( 0.23 vs. 0.85 , respectively). No significant difference was noted in the pattern of response to the novel isoamyl acetate odor (excitation ratio $=1.0$ for both groups).

\section{DISCUSSION}

The data presented here indicate that the same constraints that govern the acquisition of a classically conditioned olfactory behavioral response also appear to govern the acquisition of the olfactory bulb neural modifications. Only temporally forward presentations of the CS and US resulted in the acquisition of the odor preference, enhanced 2-DG uptake, and modified mitral/tufted cell responding. Temporally backward presentation of the CS and US resulted in none of these changes, and resulted in responses similar to those reported for naive pups (Sullivan \& Leon, 1986; Wilson et al., 1985, 1987).

The fact that acquisition of both the behavioral and neural responses required forward CS-US pairings raises the question of the neural substrates of the CS-US association. That is, how does the neural trace for odor input come to be associated with the neural trace for tactile stimulation? Interestingly, the olfactory bulb is uniquely situated anatomically for precisely this type of association. The olfactory bulb is the first relay station in the olfactory system, receiving direct olfactory nerve input. The bulb also receives a massive input from the noradrenergic nucleus locus coeruleus (Shipley, Halloran, \& De la Torre, 1985). Locus coeruleus neurons respond to tactile stimulation as soon as $\mathbf{1}$ day after birth (Nakamura, Kimura, \& Sakaguchi, 1987), and the noradrenergic input to the bulb is present (McLean \& Shipley, 1987) and functional (Wilson \& Leon, 1988a) during the first postnatal week. Thus, the co-occurrence of primary olfactory nerve input and stroking-induced noradrenergic input from the locus coeruleus may result in the neurobehavioral changes we have observed after early olfactory conditioning. If these inputs do not cooccur, as in backward conditioning, no changes are observed. In support of this hypothesis, we have recently demonstrated that stroking can be replaced by noradrenergic beta-receptor agonists during conditioning and that beta-receptor antagonists can block early learning (Sullivan, Wilson, \& Leon, 1988).

\section{REFERENCES}

Astic, L., \& CATARELli, M. (1982). Metabolic mapping of functional activity in the rat olfactory system after a bilateral transection of the lateral olfactory tract. Brain Research, 245, 17-25.

Astic, L., SAUCIER, D. (1982). Metabolic mapping of functional ac- tivity of rat olfactory bulb: Autoradiographic study with the 2deoxyglucose method. Developmental Brain Research, 2, 243-256. BARNeTT, S. A., WALKer, K. Z. (1974). Early stimulation, parental behavior, and the temperature of infant mice. Developmental Psychobiology, 7, 563-577.

Butler, S. R., Suskind, M. R., \& Schanberg, S. M. (1968). Maternal behavior as a regulator of polyamine biosynthesis in brain and heart of developing rat pup. Science, 199, 445-447.

CoOpersmith, R., \& LeON, M. (1984). Enhanced neural response to familiar olfactory cues. Science, 225, 849-851.

CoOpersmith, R., \& LeON, M. (1986). Enhanced neural response by adult rats to odors experienced early in life. Brain Research, 371, 400-403.

Cornwell-Jones, C., \& Sobrian, S. K. (1977). Development of olfactory guided behavior in Wistar and Sprague-Dawley rat pups. Physiology \& Behavior, 19, 685-688.

Evoniuk, G. E., Kunn, C. M., \& Schanberg, S. M. (1978). The effect of tactile stimulation on serum growth hormone and tissue ornithine decarboxylase in rat pups. Communications in Psychopharmacology, 3, 363-370.

Gallistel, C. R., Piner, C., Allen, T. O., Adler, N. T., YADIN, E., \& NEGIN, M. (1982). Computer assisted analysis of 2-DG autoradiography. Neuroscience \& Biobehavioral Reviews, 6, 409-420.

Greer, C. A., Stewart, W. B., Kauer, J. S., \& Shepherd, G. M. (1981). Topographical and laminar localization of 2-deoxyglucose uptake in rat olfactory bulb induced by electrical stimulation of olfactory nerves. Brain Research, 217, 279-293.

Johanson, I. B., \& HALL, W. G. (1982). Appetitive conditioning in neonatal rats: Conditioned orientation to a novel odor. Developmental Psychobiology, 15, 379-397.

Johanson, I. B., Polefrone, J. M., \& Hall, W. G. (1984). Appetitive conditioning in neonatal rats: Conditioned ingestive responding to stimuli paired with oral infusions of milk. Developmental Psychobiology, 17, 357-381.

Johanson, I. B., \& Teicher, M. (1980). Classical conditioning of an odor preference in 3-day-old rats. Behavioral \& Neural Biology, 29, 132-136.

Jourdan, F., Duveau, A., Astic, L., \& Holley, A. (1980). Spatial patterns of [14C]2-deoxyglucose uptake in the olfactory bulb of rats stimulated with two different odors. Brain Research, 188, 139-154.

KeLLY, P. A. T., \& MCCullough, T. (1981). Errors associated with modifications of quantitative 2-deoxyglucose technique. Journal of Cerebral Blood Flow \& Metabolism, 1(Suppl.), 60-61.

Kuhn, C. M., Butler, S. R., \& Schanberg, S. M. (1978). Selective depression of serum growth hormone during maternal deprivation in rat pups. Science, 201, 1034-1036.

Leon, M. (1974). The maternal pheromone. Physiology \& Behavior, $13,441-453$.

Leon, M., Coopersmith, R., Lee, S., Sullivan, R. M., Wilson, D. A., Woo, C. (1987). Neural and behavioral plasticity induced by early olfactory experience. In N. Krasnegor, E. Blass, M. Hofer, \& W. Smotherman (Eds.), Perinatal development: A psychobiological perspective (pp. 145-167). New York: Academic Press.

McLean, J. H., \& ShIPLEY, M. T. (1987). Postnatal development of noradrenergic afferents to the olfactory bulb. Association for Chemoreception Sciences Abstracts, 9, 169.

Nakamura, S., Kimura, F., \&akaguchi, T. (1987). Postnatal development of electrical activity in the locus coenuleus. Journal of Neurophysiology, 58, 510-524.

Pavlov, I. P. (1927). Conditioned reflexes. New York: Oxford University Press.

Rescorla, R. A. (1967). Pavlovian conditioning and its proper control procedures. Psychological Reviews, 74, 71-81.

SChanberg, S. M., EvoniuK, G., \& KUHN, C. M. (1984). Tactile and nutritional aspects of maternal care: Specific regulators of neuroendocrine function and cellular development. Proceedings of the Society for Experimental \& Biological Medicine, 175, 135-146.

SHARP, F., KAUER, J., \& SHEPHERD, G. M. (1975). Local sites of activity related glucose metabolism in rat olfactory bulb during olfactory stimulation. Brain Research, 98, 596-600. 
Sharp, F. R. Kilduff, T. S., Bzorgchami, S., Heller, H. \& Ryan, A. F. (1983). The relationship of local cerebral glucose utilization to optical density ratios. Brain Research, 263, 97-103.

Shipley, M. T.. Halloran, F., \& De la Torre, J. (1985). Suprisingly rich projection from locus coeruleus to the olfactory bulb in the rat. Brain Research, 329, 294-299.

Sokoloff, L., Reivich, M., Kennedy, C., Des Rosiers, M., Patlak, C., Pettigrew, K., Sakurada, O., \& Shinohara, M. (1977). The $[14 \mathrm{C}] \mathrm{C}$ deoxyglucose method for measurement of local cerebral glucose utilization: Theory, procedure, and normal values in the conscious and anesthetized albino rat. Journal of Neurochemistry, 28, 897-916.

Stewart, W. B., Kauer, J. S., \& ShePherd, G. M. (1979). Functional organization of rat olfactory bulb analysed by the 2-deoxyglucose method. Journal of Comparative Neurology, 185, 715-734.

Sullivan, R. M., Brake, S. C., Hofer, M. A., \& Williams, C. L. (1986). Huddling and independent feeding of neonatal rats is enhanced by a conditioned change in behavioral state. Developmental Psychobiology, 19, 625-635.

Suluvan, R. M., \& HALL, W. G. (1988). Reinforcers in infancy: Classical conditioning using stroking or intra-oral infusions of milk as a UCS. Developmental Psychobiology, 21, 215-223.

Sullivan, R. M., Hofer, M. A., \& Brake, S. C. (1986). Olfactoryguided orientation in neonatal rats is enhanced by a conditioned change in behavioral state. Developmental Psychobiology, 19, 615-623.

SUlLIVAN, R. M., \& LEON, M. (1986). Early olfactory learning induces an enhanced olfactory bulb response in young rats. Developmental Brain Research, 27, 278-282.

Sullivan, R. M., \& LeON, M. (1987). One-trial olfactory learming en- hances olfactory bulb responses to an appetitive conditioned odor in 7-day-old rats. Developmental Brain Research, 35, 301-311.

Suluivan, R. M., Wilson, D. A., \& Leon, M. (in press). Behavioral and neural correlates of postnatal olfactory conditioning: IV. The role of NE during conditioning. Journal of Neuroscience.

Sullivan, R. M., WILSON, D. A., KIM, M. H., Leon, M. (1988). Behavioral and neural correlates of postnatal olfactory conditioning: I. Effects of respiration on conditioned neural responses. Physiology \& Behavior, 44, 85-90.

Wilson, D. A., \& LEON, M. (1988a). Noradrenergic modulation of olfactory bulb excitability in the postnatal rat. Developmental Brain Research, 42, 69-75.

WILSON, D. A., LEON, M. (1988b). Spatial patterns of olfactory bulb single-unit responses to learned olfactory cues in young rats. Journal of Neurophysiology, 59, 1770-1782.

Wilson, D. A., Sulluvan, R. M., \& Leon, M. (1985). Odor familiarity alters mitral cell response in the olfactory bulb of neonatal rats. Developmental Brain Research, 22, 314-317.

Wilson, D. A., Sullivan, R. M., \& Leon, M. (1987). Single-unit analysis of postnatal olfactory learning: Modified olfactory bulb output response patterns to learned attractive odors. Journal of Neuroscience, 7, 3154-3162.

Woo, C. C., LEON, M. (1987). Sensitive period for neural and behavioral response development to learned odors. Developmental Brain Research, 36, 309-313.

(Manuscript received August 11, 1988; revision accepted for publication November 7,1988 .) 